Published in final edited form as:

Biochemistry. 2020 April 14; 59(14): 1442-1453. doi:10.1021/acs.biochem.0c00001.

\title{
Subunit Interaction Dynamics of Class la Ribonucleotide Reductases: In Search of a Robust Assay
}

\author{
Kanchana Ravichandran ${ }^{a}$, Lisa Olshansky ${ }^{a, b}$, Daniel G. Nocerab ${ }^{b}$, JoAnne Stubbe ${ }^{a, c,{ }^{*}}$ \\ aDepartment of Chemistry, Massachusetts Institute of Technology, 77 Massachusetts Avenue, \\ Cambridge, MA 02139 \\ bDepartment of Chemistry and Chemical Biology, Harvard University, 12 Oxford Street, \\ Cambridge, MA 02138 \\ 'Department of Biology, Massachusetts Institute of Technology, 77 Massachusetts Avenue, \\ Cambridge, MA 02139
}

\begin{abstract}
Ribonucleotide reductases (RNRs) catalyze the conversion of nucleotides (NDP) to deoxynucleotides (dNDP), in part controlling the ratios and quantities of dNTPs available for DNA replication and repair. The active form of $E$. coli class Ia RNR is an asymmetric $\alpha_{2} \beta_{2}$ complex in which $a_{2}$ contains the active site and $\beta_{2}$ contains the stable diferric-tyrosyl radical cofactor responsible for initiating the reduction chemistry. Each dNDP is accompanied by disulfide bond formation. We now report that $\beta_{2}$ can act catalytically when assaying RNR in either the absence or presence of an external reductant. In the absence of reductant, rapid chemical quench analysis of a reaction of $a_{2}(10 \mu \mathrm{M})$, substrate, and effector with variable amounts of $\beta_{2}$ $(0.1,1$ or $10 \mu \mathrm{M})$ yields $3 \mathrm{dCDP} / \mathrm{a}_{2}$ at all ratios of $\mathrm{a}_{2}: \beta_{2}$ with a rate constant of $8-9 \mathrm{~s}^{-1}$, associated with a rate limiting conformational change(s). Stopped-flow fluorescence spectroscopy with a fluorophore-labeled $\beta$ reveals that the rate constants for subunit association $\left(163 \pm 7 \mu \mathrm{M}^{-1} \mathrm{~s}\right.$ $\left.{ }^{-1}\right)$ and dissociation $\left(75 \pm 10 \mathrm{~s}^{-1}\right.$ ) are fast relative to turnover, consistent with catalytic $\beta_{2}$. When assaying in the presence of an external reducing system, the turnover number is dictated by the ratio of $a_{2}: \beta_{2}$, their concentrations, and the concentration and nature of the reducing system; the
\end{abstract}

\footnotetext{
“Corresponding Author: stubbe@ mit.edu.

UniProt NUMBERS

E.coli nrdA - P00452

E. coli nrdB - P69924

B. subtilis nrdE - P50620

B. subtilis $\mathrm{nrdF}-\mathrm{P} 50621$

S. Sanguinis nrdE - A3CLZ6

S. sanguinis nrdF - A3CLZ4

M. tb nrdE - P9WH75

M. tb nrdF - P9WH71

Human RRM1 - P23921

Human RRM2 - P31350

ASSOCIATED CONTENT

Observed dCDP production in the presence of pathway-blocked variants $\mathrm{Y}_{356} \mathrm{~F}-\beta_{2}$, and $\mathrm{Y}_{731} \mathrm{~F}-\mathrm{a}_{2}$, previously reported turnover kinetics $^{14}$ in the presence of TR/TRR/NADPH, pre-steady state single turnover kinetics of dCDP formation, RNR assays in the presence of optimized endogenous reductant with $a: \beta(1: 1)$ at increasing concentrations. This material is available free of charge via the Internet at http://pubs.acs.org.
} 
rate-limiting step can change from the conformational gating, to a step or steps involving disulfide re-reduction, dissociation of the inhibited $\alpha_{4} \beta_{4}$ state or both. The issues encountered in the E. coli RNR assays are likely of importance in all class I RNR assays and are central to understand in developing screening assays for inhibitors of these enzymes.

\section{Graphical Abstract}
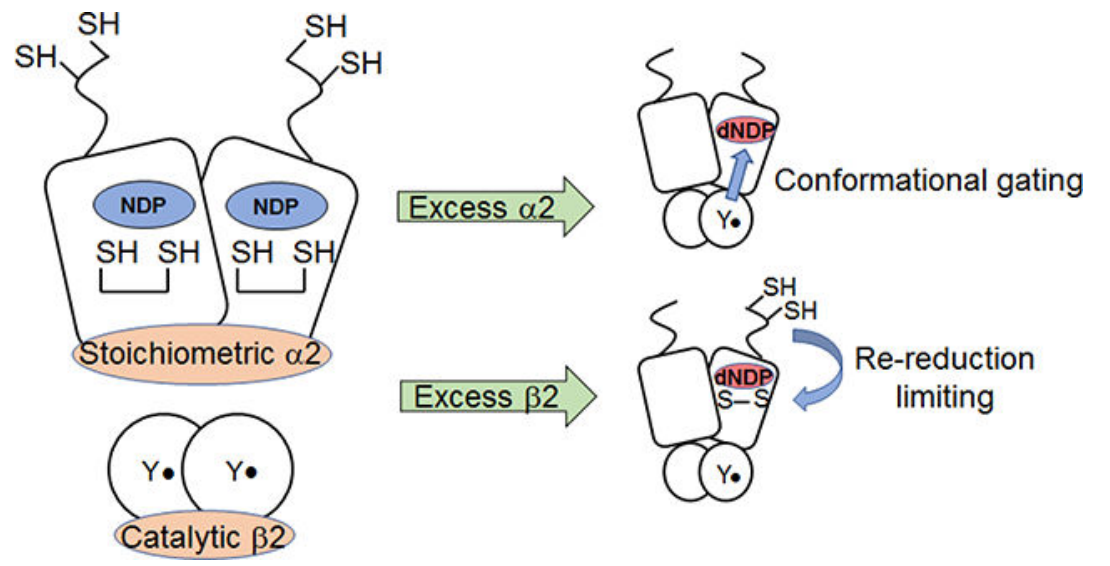

\section{INTRODUCTION}

E. coli class Ia ribonucleotide reductase (RNR) catalyzes the conversion of nucleoside $5^{\prime}$ diphosphates (CDP, UDP, GDP, ADP) to their corresponding deoxynucleotides (dNDPs), providing the essential building blocks for DNA replication and repair. ${ }^{1,2}$ The E. coli Ia enzyme, a paradigm for class I RNRs, consists of two homodimeric subunits, $a_{2}$ and $\beta_{2}$, that are active in an asymmetric, tetrameric $\alpha_{2} \beta_{2}$ complex. ${ }^{3-6}$ The diferric-tyrosyl radical $\left(\mathrm{Y}_{122^{\circ}}\right)$ located in $\beta_{2}$ generates a transient thiyl radical in $\alpha_{2}\left(C_{439^{\circ}}\right)$ subsequent to its binding NDP and effector, which then initiates NDP reduction. This reversible oxidation process occurs over a distance of $\sim 35 \AA$ and involves a pathway of conserved aromatic amino acid residues and a cysteine. ${ }^{6,7}$

The central role of RNRs in nucleic acid metabolism has made the human RNR the target of five clinically used therapeutics that inhibit distinct steps in the reduction process. ${ }^{8-10}$ The limiting factor in identifying new types of RNR inhibitors has been the development of rapid in vitro and in vivo screens for enzyme activity. In a recent study with an RNR containing a site-specifically incorporated unnatural amino acid, we identified the ability of a mutant $\beta_{2}$ to act catalytically in $a_{2}$ turnover. ${ }^{11}$ We now report that wt $\beta_{2}$ can also act catalytically in pre-steady state and steady state assays. In support of this result, the kinetics of $\alpha / \beta$ subunit interactions are fast relative to enzymatic turnover. Consideration of the dynamics of these inter-subunit interactions are important in designing assays for RNR activity and screening for RNR inhibitors.

In early studies to purify $E$. coli RNR, ${ }^{12}$ the two subunits separated and required recombination for activity measurement. The $K_{\mathrm{d}}$ for subunit interaction was subsequently established to be $0.4 \mu \mathrm{M}$ in the apo form and to increase to $0.2 \mu \mathrm{M}$ on binding of NDP and 
its matched allosteric effector. ${ }^{13}$ Since that time, RNR subunits have typically been assayed independently, using a physiological concentration of one subunit $(0.1-0.5 \mu \mathrm{M})$ and a 5 to 10 -fold excess of the second subunit to ensure "active" $a_{2} \beta_{2}$ complex formation. However, the activity of $\alpha_{2}$ is always less than that of $\beta_{2},{ }^{14}$ suggesting that the amount of $\alpha_{2} \beta_{2}$ complex alone does not govern activity.

RNR assays are typically carried out under two sets of conditions in the absence and presence of endogenous reductant. Our recent model for dNDP formation in the absence of endogenous reducing system (steps A-G) and in its presence (step H) is shown in Scheme 1. ${ }^{15}$ Many distinct perturbative biochemical studies and recent structural studies of an active $\mathrm{a}_{2} \beta_{2}$ double mutant $\left(\mathrm{F}_{3} \mathrm{Y}_{122} / \mathrm{E}_{52} \mathrm{Q}-\beta_{2} / \mathrm{a}_{2} / \mathrm{GDP} / \mathrm{TTP}\right)$ establish asymmetry within the "active" complex. ${ }^{15}$ We propose a model in which $a_{2}$, loaded with substrate (CDP) and allosteric effector (ATP), binds to $\beta_{2}$ and that one dCDP is formed in an $\alpha / \beta$ pair before triggering formation of a second $\mathrm{dCDP}$ in the adjacent $\alpha / \beta$ pair. In the wt enzyme, $2 \mathrm{dCDPs}$ are generated at $\sim 5-10 \mathrm{~s}^{-1} .{ }^{14} \mathrm{In}$ all the perturbative systems examined, the asymmetry becomes apparent as the switching between the two $\alpha / \beta$ pairs is altered. For the wt system, each dCDP is accompanied by the oxidation of a $\mathrm{C}_{225}, \mathrm{C}_{462}$ pair to a disulfide. The $C$ terminal tail of each a monomer contains two additional conserved cysteines $\left(\mathrm{C}_{754}, \mathrm{C}_{759}\right)$ that are involved in re-reduction of the active site disulfide in their own monomer. ${ }^{16}$ While the details of the re-reduction are not established, the structure suggests that the subunits likely dissociate or may undergo a slow conformational reorganization so that two more dCDPs can be generated (step G, Scheme 1) at a rate constant of $\sim 0.1 \mathrm{~s}^{-1}$. While a maximum of $4 \mathrm{dCDPs} / \mathrm{a}_{2}$ can be generated, only 2.5-3 dCDPs are routinely measured. We attribute this observation to $a_{2}$ 's sensitivity to oxidation during its purification and/or handling. Under typical assay conditions for E. coli RNR, in the presence of endogenous reductants thioredoxin (TR), thioredoxin reductase (TRR) and NADPH, $\alpha_{2}$ generates many $\mathrm{dCDPs}\left(\right.$ step $\mathrm{H}$ ) with a rate constant of $1-2 \mathrm{~s}^{-1}$, that is likely associated with the complexity of $C$-terminal tail mediated re-reduction and the role of the thioredoxin. ${ }^{17,18}$

Unlike $a_{2}$, the $Y \bullet$ in $\beta_{2}$ is regenerated immediately following dCDP formation. ${ }^{11}$ This scenario makes it feasible that each $\beta_{2}$ can service multiple $\alpha_{2}$ s and that fast subunit dissociation and re-association to $\alpha_{2} \beta_{2}$ followed by rapid chemistry, could preclude observation of these dynamics. We hypothesize that catalytic $\beta_{2}$ might account for the differences in the turnover number of $\alpha_{2}$ and $\beta_{2}$.

In the current study, we describe experiments to examine the ability of $\beta_{2}$ to act catalytically in the absence and in the presence of an external reducing system. In the absence of reductant and at ratios of $a: \beta$ from 1:1, 10:1 and 100:1, $\sim 3 \mathrm{dCDP} / \mathrm{a}_{2}$ are generated with a rate constant of $8 \mathrm{~s}^{-1}$ relative to $\mathrm{Y}^{*}$. When the $\alpha: \beta$ ratio is $100: 1,200$ turnovers occur. Rate constants for association $\left(163 \pm 7 \mu \mathrm{M}^{-1} \mathrm{~s}^{-1}\right)$ and dissociation $\left(75 \pm 10 \mathrm{~s}^{-1}\right)$ of $\alpha_{2}$ and $\beta_{2}$, measured by stopped-flow fluorescence spectroscopy using $\beta_{2}$ modified site-specifically with an environmentally sensitive fluorophore, support a catalytic role for $\beta_{2}$. In the presence of endogenous reductant, we also establish that $\beta_{2}$ can function catalytically. However, under the conditions of limiting $a_{2}$ or at high concentrations of the subunits ( 1 $10 \mu \mathrm{M})$, the rate-limiting step switches from the conformational gating of radical transfer (RT) chemistry to re-reduction of $a_{2}$, likely involving conformational change(s) ${ }^{15}$ or 
interconversion of active and inactive quaternary structures of RNR $\left(\alpha_{2} \beta_{2}\right.$ and $\alpha_{4} \beta_{4}$ in $E$. colit ${ }^{19}$ or both.

The observations that (i) $\beta_{2}$ can function catalytically, (ii) the discoveries of the complexity of a's quaternary structures and their dependence on concentration of protein and (deoxy)nucleotides, (iii) incompletely loaded metallocofactor in $\beta$, and (iv) the instability of $\alpha$ to oxidation and its propensity to aggregate require consideration when developing assays for both old and new RNRs. These issues lead us to suggest a standard way to assay RNRs that is distinct from the one that has been used for the past few decades.

\section{MATERIALS AND METHODS}

\section{Materials}

His $_{6}-\mathrm{a}_{2}$, specific activity (SA) of $2500 \mathrm{nmol}(\mathrm{min}-\mathrm{mg})^{-1}$ and wt $-\beta_{2}$ with $1.2 \mathrm{Y} \bullet / \beta_{2}$, SA of $6000 \mathrm{nmol}(\mathrm{min}-\mathrm{mg})^{-1}$ were expressed from the pET28a-nrdA and pTB2-nrdB plasmids and purified as previously described. ${ }^{20,21}$ The diferric-tyrosyl radical in $\beta_{2}$ is always generated by self-assembly, ${ }^{22}$ and by our method ${ }^{23}$ gives $1.2 \mathrm{Y} \bullet \mathrm{s}$ that we believe are unequally distributed between each $\beta_{2}$. Sixty percent of $\beta_{2}$ is active and $40 \%$ contains a diferric-center with no radical, is inactive and termed met- $\beta_{2}$. $\alpha_{2}$ was pre-reduced prior to use with dithiothreitol (DTT) and treated with hydroxyurea (HU) to reduce the tyrosyl radical in the small amount of $\beta_{2}$ that always co-purifies with $a_{2} \cdot{ }^{24}$ E. coli thioredoxin, TR $(40 \mathrm{U} / \mathrm{mg})$ and thioredoxin reductase, TRR (1400 U/mg) were purified using established protocols. ${ }^{25,26} 6$ Bromoacetyl-2-dimethylaminonaphthalene (BADAN) was purchased from Molecular Probes (Eugene, OR). $\mathrm{C}_{268} \mathrm{~S} / \mathrm{C}_{305} \mathrm{~S} / \mathrm{V}_{365} \mathrm{C}-\beta_{2}$ was isolated and labeled with BADAN to make dansyl- $\beta_{2}$ as previously described. ${ }^{27}$ For stopped flow (SF) fluorescence spectroscopy experiments, $Y_{122}$ of wt- $\beta_{2}$ or (dansyl- $\beta_{2}$ ) was reduced by treatment of $\beta_{2}$ with HU. [5- ${ }^{3} \mathrm{H}$ ]CDP was obtained from Vitrax (Placentia, CA). Calf alkaline phosphatase was purchased from Roche. Assay buffer is $50 \mathrm{mM}$ HEPES, $15 \mathrm{mM} \mathrm{MgSO}_{4}$ and $1 \mathrm{mM}$ EDTA (pH 7.6).

\section{dCDP formation kinetics as a function of subunit ratio with no endogenous reductant}

Rapid Chemical Quench (RCQ) experiments were performed on a Kintek RQF-3 instrument attached to an external circulating water bath set at $25^{\circ} \mathrm{C}$. To assess the effect of $\left[\beta_{2}\right]$ on kinetics, wt- $a_{2}(20 \mu \mathrm{M})$ and ATP $(6 \mathrm{mM})$ in assay buffer in syringe A was rapidly mixed with wt $-\beta_{2}\left(0.2,2\right.$ or $20 \mu \mathrm{M}$ and $\left[5-{ }^{3} \mathrm{H}\right]-\mathrm{CDP}(1 \mathrm{mM}, 20,000 \mathrm{cpm} / \mathrm{nmol})$ in an equal volume from syringe $\mathrm{B}$. The reaction was quenched in the instrument $(5 \mathrm{~ms}-100 \mathrm{~s})$ or by hand (> $100 \mathrm{~s}$ ) in $2 \% \mathrm{HClO}_{4}$ and samples were dephosphorylated and worked up as previously described. ${ }^{14,28}$ To assess the effect of $\left[\alpha_{4} \beta_{4}\right]$ on dCDP formation kinetics, a control reaction of wt- $a_{2}(1 \mu \mathrm{M})$, wt- $\beta_{2}(1 \mu \mathrm{M}),\left[5-{ }^{3} \mathrm{H}\right]-\mathrm{CDP}(0.5 \mathrm{mM})$ and ATP $(3 \mathrm{mM})$ was also monitored by RCQ. Data were fit to Eq. 1 (for 1:1 and 10:1 $\mathrm{a}_{2}: \beta_{2}$ ), and Eq. 2 (for 100:1 $\mathrm{a}_{2}: \beta_{2}$ ) to obtain $k_{\text {cat }}$ from the sum of $\mathrm{A}_{1} k_{1}+\mathrm{A}_{2} k_{2}$.

$$
y=A_{1}\left(1-e^{-k_{1} t}\right)+A_{2}\left(1-e^{-k_{2} t}\right)
$$




$$
y=A\left(1-e^{-k t}\right)
$$

\section{Association and dissociation rate constants by SF fluorescence spectroscopy}

$k_{\text {assoc }}$ and $k_{\text {dissoc }}$ for the $\alpha_{2} \beta_{2}$ complex in the presence and absence of CDP, ATP, and dATP were determined by SF fluorescence spectroscopy using an Applied Photophysics DX.17MV instrument equipped with the Pro-Data upgrade. The temperature was maintained at $22.0 \pm 0.1{ }^{\circ} \mathrm{C}$ with a Lauda RE106 circulating water bath and all samples were incubated for $3 \mathrm{~min}$ at this temperature prior to measurement. Total fluorescence at $\lambda>420 \mathrm{~nm}$ was detected by a PMT with a long pass filter, using an excitation bandwidth of $40 \mathrm{~nm}$ centered at $390 \mathrm{~nm}$. All solutions were prepared in assay buffer. Association rate constants were determined by rapid mixing of $1-6 \mu \mathrm{M}$ of $\mathrm{a}_{2}, \pm \mathrm{CDP}(0.4 \mathrm{mM})$, and \pm ATP $(1.2 \mathrm{mM})$ in one syringe with an equal volume of $0.16 \mu \mathrm{M}$ dansyl $-\beta_{2}$ in a second syringe. The reaction was iterated to obtain $\sim 50$ traces that were then averaged and fit to Eq. 2 to obtain $k_{o b s}$. Plotting $k_{o b s}$ as a function of $\left[a_{2}\right]$ provided $k_{\text {assoc }}$ from the slope of the linear fit to Eq. 3 derived from a one-step reversible binding model for pseudo-first order conditions. This process was repeated three times and reported error reported accounts for error between replicates as well as error associated with the goodness of fit.

$$
k_{o b s}=k_{a s s o c}\left[\alpha_{2}\right]+k_{d i s s o c}
$$

As determination of $k_{\text {dissoc }}$ by extrapolation of Eq. 3 to [a $\left.a_{2}\right]=0$ gives significant error, $k_{\text {dissoc }}$ was measured directly by mixing equal volumes of dansyl- $\beta_{2}(0.2 \mu \mathrm{M}), \alpha_{2}(0.5 \mu \mathrm{M})$, $\pm \mathrm{CDP}(0.5 \mathrm{mM})$ and \pm ATP $(1.2 \mathrm{mM})$ or $\pm \mathrm{dATP}(100 \mu \mathrm{M})$ in one syringe with a large excess of met- $\beta_{2}(100 \mu \mathrm{M})$ in a second syringe with the same CDP/ATP. A minimum of 15 traces was averaged per trial and 3-6 independent trials were conducted for each condition (in the presence and absence of CDP and/or ATP). With the exception of dissociation rate constants measured in the presence of dATP, all SF fluorescence traces were well fit to a monoexponential function (Eq. 2) over 1-75 ms. In the presence of dATP, dissociation kinetics were biphasic and fit to Eq. 1 over $0.001-8 \mathrm{~s}$. All fitting was performed using OriginPro 8.0 software (OriginLab). Acceptability of fitting was determined on the basis of qualitative symmetry of residuals about zero amplitude and the $R^{2}$ factor.

\section{dCDP formation kinetics as a function of subunit ratio in the presence of TR/TRR/NADPH}

RCQ experiments were performed identically to those described above in the absence of reductant with the following minor modifications. Syringe A included TR $(80 \mu \mathrm{M})$, TRR $(1.6 \mu \mathrm{M})$ in addition to wt- $\mathrm{a}_{2}(20 \mu \mathrm{M})$ and ATP $(6 \mathrm{mM})$, while syringe B contained wt $-\beta_{2}$ $(0.2$ or $20 \mu \mathrm{M}),\left[5-{ }^{3} \mathrm{H}\right]-\mathrm{CDP}(2 \mathrm{mM}, 20,000 \mathrm{cpm} / \mathrm{nmol})$ and NADPH $(2 \mathrm{mM})$. Data were fit to Eq. 4 (for 1:1 and 10:1 $a_{2}: \beta_{2}$ ), and Eq. 5 (for 100:1 $a_{2}: \beta_{2}$ ) where A and $k_{\text {burst }}$ are the amplitude and observed rate constant for the burst phase, respectively, and $k_{\text {linear }}$ is the steady-state turnover number $\left(k_{\text {cat }}\right)$. 


$$
\begin{gathered}
y=A\left(1-e^{k_{\text {burst }} t}\right)+k_{\text {linear }} t \\
y=k_{\text {linear }} t+c
\end{gathered}
$$

\section{Steady-state turnover kinetics}

Assays contained a reaction mixture of $170 \mu \mathrm{L}$ : wt- $\mathrm{a}_{2}(1-10 \mu \mathrm{M})$, wt- $\beta_{2}(0.1-10 \mu \mathrm{M})$, $\left[5-{ }^{3} \mathrm{H}\right]-\mathrm{CDP}(8,000 \mathrm{cpm} / \mathrm{nmol}, 0.5 \mathrm{mM})$, ATP $(3 \mathrm{mM})$, TR $(40 \mu \mathrm{M})$, TRR $(0.8 \mu \mathrm{M})$ and NADPH $(1 \mathrm{mM})$. Aliquots $(40 \mu \mathrm{L})$ were quenched at $30 \mathrm{~s}, 1,2$ and 3 min in $25 \mu \mathrm{L}$ of $2 \%$ $\mathrm{HClO}_{4}$. Product separation was performed as described by Steeper and Steuart. ${ }^{28}$

\section{Kinetics of dimanganese tyrosyl radical RNR (NrdF2-NrdE) with NrdH exogenous reductant}

NrdI was purified to homogeneity and used to assemble the dimanganese-tyrosyl radical cofactor in NrdF2. Typically, $0.7 \mathrm{Y} \bullet / \beta$ were obtained for cluster assembled in NrdF2. In our hands, NrdF1 was always in inclusion bodies. NrdE was purified under a variety of conditions and in all cases its solubility was limited $(\sim 10 \mu \mathrm{M})$. Full length NrdE, with no tag, was used in these assays. Purification of thioredoxin equivalents (TrxA, TrxB1, Trxc and $\mathrm{NrdH}$ ) as well as thioredoxin reductase were carried out and examined for activity. $\mathrm{NrdH}$ was established to be the physiological reductant.

\section{RESULTS}

\section{Effect of catalytic $\beta_{2}$ on inactive site-directed mutants of RNR}

Since RNR is essential for $E$. coli viability, over-expression of either mutant $\alpha_{2}$ or $\beta_{2}$ always results in small amounts of co-purifying endogenous subunits. ${ }^{29}$ For example, $\mathrm{Y}_{356} \mathrm{~F}-\beta_{2}$, a variant incapable of dNDP formation, ${ }^{30}$ typically contains between $0.1-5 \%$ contaminating $\mathrm{wt}-\beta_{2}$. When product formation is examined for a reaction mixture containing $0.34 \mathrm{nmol}$ each of $\mathrm{Y}_{356} \mathrm{~F}-\beta_{2}$ and wt- $\alpha_{2}, \mathrm{CDP}$, and ATP in the absence of a reducing system, increasing amounts of dCDP are observed with time such that $1.5 \mathrm{dCDP} / \mathrm{a}_{2}$ are produced within 15 $\min$ (Fig. S1). If $\beta_{2}$ is not catalytic with respect to $\alpha_{2}$, one would predict that turnover in the absence of a reducing system would result in $0.003-0.15 \mathrm{dCDP} / \mathrm{a}_{2}$. The observation of a $10-500$-fold enhancement over the expected number of dCDPs suggests that one $\beta_{2}$ can service multiple $a_{2}$ s. In contrast to $\mathrm{Y}_{356} \mathrm{~F}-\beta_{2}$, when similar experiments are performed with another catalytically inactive mutant, $\mathrm{Y}_{731} \mathrm{~F}-\mathrm{a}_{2},{ }^{31}$ only $0.05-0.09 \mathrm{dCDP} / \mathrm{a}_{2}$ are generated with no visible time dependence. This observation is consistent with $2-3 \%$ contaminating wt- $a_{2}$ and a non-catalytic role for $\alpha_{2}$ with respect to $\beta_{2}$ turnover. These observations together with the observation that $\alpha_{2}$ in the presence of excess $\beta_{2}$ vs $\beta_{2}$ in the presence of excess $a_{2}$ (Fig. S2) give different turnover numbers provided the impetus for examining the reaction of wt RNR at different $\alpha: \beta$ ratios.

\section{dCDP formation kinetics as a function of subunit ratio in the absence of reductant}

To test the hypothesis that $\beta_{2}$ is catalytic, dCDP was measured at $a: \beta=1: 1,10: 1$ or 100:1

(Fig. 1) with $10 \mu \mathrm{M} \mathrm{a}_{2}$, and $\beta_{2}$ varied $(0.1,1$ or $10 \mu \mathrm{M})$. The total amount of dCDP was 
normalized per $\mathrm{a}_{2}$ or $\mathrm{Y} \bullet$ and the rate constants calculated from the sum of $\mathrm{A}_{1} k_{1}+\mathrm{A}_{2} k_{2}$ in Eqs. 1 and 2, where $\mathrm{A}_{\mathrm{n}}$ and $k_{\mathrm{n}}$ represent the amplitude and rate constant of each kinetic phase (Table 1). As seen in Fig. 1, 2.5-3 dCDP/ $\alpha_{2}$ are produced at all $a: \beta$ ratios. At $\alpha: \beta=$ 1:1 and 10:1, total dCDP production occurs over two kinetic phases: $1.3-1.4 \mathrm{dCDP} / \mathrm{a}_{2}$ are generated in the first phase and $1.1-1.6 \mathrm{dCDP} / \mathrm{a}_{2}$ in the second phase. As we previously proposed, ${ }^{14}$ the first phase reports on the generation of the first two dCDPs by each $a$ monomer, and the second phase reports on re-reduction of the active site disulfide by the $C$ terminal dithiols of $a_{2}$ (Scheme 1). Support for this interpretation is provided by the ability to generate $1.4-1.7 \mathrm{dCDP} / \mathrm{a}_{2}$ in a single kinetic phase in a mutant $\alpha_{2}$ containing serines in place of the $C$-terminal cysteines. ${ }^{14}$ At $\alpha: \beta=100: 1$, a single kinetic phase producing 2.5 $\mathrm{dCDP} / \mathrm{a}_{2}$ is observed.

In contrast, normalizing product formation relative to equivalents of $\mathrm{Y} \bullet$ reveals that a total of $1.1,10$, and $207 \mathrm{dCDP} / \mathrm{Y} \bullet$ are formed at $\alpha: \beta=1: 1,10: 1$, and 100:1, respectively (Table 1). Recalling that $\sim 60 \%$ of $\beta_{2}$ is active and contains $2 \mathrm{Y} \bullet$, the remaining $40 \%$ is inactive with only a diferric cluster. ${ }^{11}$ Thus, a single active $\beta_{2}$ performs many turnovers during the same time $a_{2}$ makes $2.5-3 \mathrm{dCDP} / \mathrm{a}_{2}$ (Fig. 1, Table 1). Calculating the turnover number relative to $\mathrm{Y} \bullet$ reveals that product formation occurs at $8-9 \mathrm{~s}^{-1}$ in all cases (Table 1). This rate constant is within the $5-10 \mathrm{~s}^{-1}$ range reported in previous studies ${ }^{14}$ and is associated with the protein conformational gating that occurs prior to initiation of the reaction. As the ratio of $\alpha: \beta$ increases, the second phase (re-reduction of the $\alpha_{2}$ active site) becomes unencumbered by the issues associated by re-reduction of the active site disulfide (Table 1, Scheme 1).

Our previous studies on wt $E$. coli RNR showed that the activity of each subunit in the presence of a 5-fold excess of the second subunit increased with concentration up to $0.5 \mu \mathrm{M}$ (Fig. S2), but that by $2 \mu \mathrm{M}$ it decreased by $50 \% .{ }^{14}$ We recently reported, using size exclusion chromatography analysis, that $\alpha_{2} \beta_{2}$ can be converted in part into an inactive $\alpha_{4} \beta_{4}$ state at concentrations $>10 \mu \mathrm{M}$ or in the presence of the negative effector dATP. ${ }^{27} \mathrm{To}$ investigate the potential effects of the $a_{4} \beta_{4}$ state on our pre-steady state kinetics measurements, we performed the 1:1 $\mathrm{a}_{2}: \beta_{2}$ experiment at low $(1 \mu \mathrm{M})$, and high $(10 \mu \mathrm{M})$ subunit concentrations (Fig. S3, Table 1). No differences were observed in dCDP formation. This result suggests that if $\alpha_{4} \beta_{4}$ forms under these experimental conditions that it rapidly reverts back to $a_{2} \beta_{2}$.

\section{Measurement of $\alpha_{2} \beta_{2}$ subunit association ( $\left.k_{\text {assoc }}\right)$ and dissociation ( $\left.k_{\text {dissoc }}\right)$ rate constants by stopped-flow fluorescence spectroscopy}

For $\beta_{2}$ to function catalytically, dissociation and re-association of the active $\alpha_{2} \beta_{2}$ complex must be fast relative to the rate limiting processes. To study this possibility, we prepared $\beta_{2}$ that contains an environmentally sensitive fluorophore site-specifically attached to a cysteine at position 365 within its $C$-terminal tail that is largely responsible for the binding affinity to $a_{2} \cdot{ }^{13,30}$ This dansyl- $\beta_{2}$ exhibits increased fluorescence intensity when the probe is situated in a hydrophobic environment compared to its fluorescence intensity free in buffered solution, providing a method to explore subunit oligomerization. ${ }^{19,27}$

To measure the rate constant for $k_{\text {assoc }}$ for $\alpha_{2} \beta_{2}$, stopped-flow (SF) fluorescence experiments were performed at varying concentrations of $a_{2}$ in $>10$-fold excess relative to 
dansyl- $\beta_{2}(80 \mathrm{nM})$ for a range of $\left[\mathrm{a}_{2}\right]$ (Fig. 2a). The subunits were rapidly mixed and the increases in fluorescence, shown in Fig. 2b, were fit to Eq. 2 for each [ $\left.a_{2}\right]$. Plotting the resulting $k_{\text {obs }}$ versus [ $a_{2}$ ] (Fig. 2c) provided $k_{\text {assoc }}$ from a linear fit to Eq. 3. These experiments were performed in the presence and absence of CDP/ATP and yielded $k_{\text {assoc }}$ that were similar and range from $150-200 \mu \mathrm{M}^{-1} \mathrm{~s}^{-1}$ (Table 2).

Dissociation rate constants ( $\left.k_{\text {dissoc }}\right)$ were determined by rapid mixing of $\alpha_{2}\left(\right.$ dansyl- $\left.\beta_{2}\right)$ complex (or $\alpha_{4}$ (dansyl- $\left.\beta_{2}\right)_{2}$ in the case with $50 \mu \mathrm{M}$ dATP) with a large excess of wt $\beta_{2}$ (Fig. 3a). In the absence and presence of CDP and ATP, the loss in fluorescence intensity was fit to a monoexponential decay, Eq. 2, to provide $k_{\text {dissoc }}$ values of $75-100 \mathrm{~s}^{-1}$ (Fig. 3b, Table 2). $k_{\text {dissoc }}$ of the active $\mathrm{a}_{2} \beta_{2}$ complex is $\sim 8-12$-fold faster than the conformational change(s) (8-9 $\mathrm{s}^{-1}$ ), supporting the proposal that a single $\beta_{2}$ can service multiple $a_{2}$ s without attenuating turnover kinetics. In contrast, when the experiment is performed in the presence of the inhibitory effector dATP, dissociation kinetics are slow and biphasic (Fig. 3c).

The oligomeric state $\left(\alpha_{2} \beta_{2}\right.$ vs $\left.\alpha_{4} \beta_{4}\right)$ of $E$. coli RNR can be controlled by protein concentration and dATP concentrations. ${ }^{3,19,32,33}$ We therefore also determined the subunit dissociation rate constant for $\alpha_{4} \beta_{4}$ generated in the presence of $50 \mu \mathrm{M}$ dATP. At these concentrations of dATP, both the specificity and activity sites of $\alpha_{2}$ are saturated, ${ }^{34,35}$ resulting in a shift toward the inactive $\alpha_{4} \beta_{4}$ state. ${ }^{3,36}$ Fitting these data to a biexponential decay (Eq. 1), each phase represents $\sim 50 \%$ of the total amplitude change and the rate constants obtained are 10- and 100-fold slower than the corresponding dissociation rate constants from the $\alpha_{2} \beta_{2}$ complex (Table 2). This is consistent with previous reports of enhanced subunit affinity in the $\alpha_{4} \beta_{4}$ state. ${ }^{19,32}$ As stated previously, $\alpha_{4} \beta_{4}$ formation that may result from high protein concentrations ( $10 \mu \mathrm{M}$ of each subunit) does not affect turnover in the absence of TR/TRR/NADPH. However, the slower dissociation kinetics of $a_{4} \beta_{4}$ could explain the range of values observed for steady state turnover in the regime where $\alpha_{2}$ becomes limiting (Table 3 ).

\section{Steady state turnover kinetics}

Studies by Ge et al. revealed that turnover number of RNR in the presence of TR/TRR/ NADPH declines with increasing protein concentration (Fig. S2). ${ }^{14}$ With these data, we proposed that the conformational change(s) prior to turnover are rate-limiting under physiological subunit concentrations $(0.1-0.5 \mu \mathrm{M})$ while some aspect of the re-reduction process governs turnover under higher protein concentrations (1-10 $\mu \mathrm{M})$. To determine if $\beta$ acts catalytically in the presence of reductant, standard RNR assays were performed at different concentrations and ratios of $a_{2}$ and $\beta_{2}$ (Table 3 ). In contrast to turnover in the absence of reductant $\left(8-9 \mathrm{~s}^{-1}\right)$, the steady-state turnover varied from 1.4 to $9 \mathrm{~s}^{-1}$. Maximal $a_{2} \beta_{2}$ activity with reductant is realized when $\left[a_{2}\right]>\left[\beta_{2}\right]$. These data combined with our previous studies ${ }^{14}$ provide further support for the catalytic role of $\beta_{2}$ during turnover. Under conditions of $\alpha: \beta=1: 1$ and subsequent to complete oxidation of $\alpha_{2}$, additional turnovers can only occur upon re-reduction by the TR/TRR/NADPH system. However, in the presence of excess $\alpha_{2}$, a single $\beta_{2}$ can "rapidly" dissociate and re-associate with multiple $\alpha_{2}$ s prior to requirement for re-reduction. Catalytic $\beta_{2}$ could explain the discrepancy between $\alpha_{2}$ and $\beta_{2}$ activities as measured by standard assays at physiological concentrations. These data further 
suggest that re-reduction is not only rate-limiting during steady-state turnover at high protein concentrations, but also under physiological concentrations when $a_{2}$ is limiting.

\section{dCDP kinetics as a function of subunit ratio in the presence of TR/TRR/NADPH}

Our previous studies monitoring dCDP formation in the presence of the TR/TRR system with $15 \mu \mathrm{M} \mathrm{a} a_{2}$ and $32 \mu \mathrm{M} \beta_{2}$, reported 1.4-1.7 dCDP/ $a_{2}$ are generated in a burst phase at $\sim 6 \mathrm{~s}^{-1}$, followed by a linear phase reporting on steady-state turnover at $0.9 \mathrm{~s}^{-1}$ (Table 4 (top row) and Fig. S2). ${ }^{14}$ These experiments provided evidence that re-reduction of $a_{2}$ by TR/TRR/NADPH is rate-determining under steady-state turnover at high protein concentrations. Given these results, and the studies above, we predicted that altering the concentration of $\beta_{2}$ in the reaction mixture would not alter the amplitude of the burst phase with respect to $a_{2}$, but that it would change when calculated relative to $\mathrm{Y} \bullet$.

RCQ experiments were therefore carried out in the presence of $a: \beta=1: 1\left(\left[\alpha_{2}\right]=\left[\beta_{2}\right]=10\right.$ $\mu \mathrm{M})$ with the prediction that the burst phase should remain constant with respect to $a_{2}$ but minimally double with respect to $\mathrm{Y} \bullet$. We found that $1.9 \pm 0.1 \mathrm{dCDP} / \mathrm{a}_{2}$ and $1.5 \pm 0.1 \mathrm{dCDP} /$ $\mathrm{Y} \bullet$ (relative to 0.7 , see Table 4 top two rows in middle column) are generated in the burst phase at $9 \pm 2 \mathrm{~s}^{-1}$ (Fig. 4a,). This result is similar to product formation kinetics and stoichiometry in the absence of TR/TRR where $\beta_{2}$ performs several turnovers, servicing all the $a_{2}$ s prior to re-reduction of the active site disulfide.

Finally, based on our current model, the $8-9 \mathrm{~s}^{-1}$ observed rate constant (Table 1) reports on the protein conformational change(s) that gates radical propagation. To support this hypothesis, we measured turnover kinetics in the presence of TR/TRR/NADPH at $a: \beta=$ 100:1. As shown in Fig. 4b, no burst phase is observed under these conditions. Instead, a linear phase for formation of product with a rate constant of $6.8 \pm 0.1 \mathrm{~s}^{-1}$ is observed. These results are consistent with the rate-determining step occurring prior to the first turnover.

\section{DISCUSSION}

Our studies in 1999 on the adenosylcoblamain (AdoCbl)-dependent Lactobacillus leichamannii ribonucleoside triphosphate reductase (RTPR) showing that AdoCbl can act catalytically, ${ }^{37}$ were in part, the inspiration for thinking about whether $\beta_{2}$ could function in a similar capacity. The RTPR system lent itself to careful kinetic analysis under two sets of conditions: $[\mathrm{AdoCbl}] \gg$ > [RTPR] and [RTPR] > [AdoCbl] in the presence of the TR/TRR reducing system. Our studies in the former case revealed that carbon-cobalt bond reformation and AdoCbl dissociation from AdoCbl•RTPR into solution can accompany every turnover, that is the radical chain length of the RTPR catalyzed dNTP reaction is $\sim 1$. In that case, the rate-limiting step is disulfide re-reduction by TR/TRR at $2 \mathrm{~s}^{-1}$. Under conditions where [RTPR] > [AdoCbl], $k_{\mathrm{cat}}$ is $15-20 \mathrm{~s}^{-1}$ and is governed by the rate constant for AdoCbl dissociation. In this situation, AdoCbl services more than one RTPR, that is, it functions catalytically. The ability of RTPR to release AdoCbl after each turnover can have important implications as previous physiological studies in L leichamannii suggested that cells produce RTPR in molar excess of AdoCbl molecules taken into cells. This strategy would thus increase the effective concentration of holo enzyme and enable a higher rate of DNA biosynthesis; elevated levels of RTPR can optimize use of scarce 
nutrients such as AdoCbl. The turnover number of $2 \mathrm{~s}^{-1}$ is very similar to the turnover number of many class I RNRs $\left(1-2 \mathrm{~s}^{-1}\right)$ when re-reduction occurs by endogenous proteins. Thus, catalytic AdoCbl in the $L$ leichmannii class II RNR set a precedent for catalytic $\beta_{2}$ in E. coli Ia RNR.

In most cases, the intracellular concentrations of the $\alpha$ and $\beta$ subunits of class I RNRs have not been measured, although with bacterial systems, where their genes reside in the same operon, it is likely that the $a / \beta$ ratio is $\sim 1: 1$. However, as in the case of RTPR, in the class Ia E. coli RNR, the availability of the active form of the metallocofactor is carefully controlled based on our studies in which the amount of $\beta_{2}$ was varied genetically and the amount of diferric cluster and tyrosyl radical was measured quantitatively. ${ }^{38}$ Future studies will be required to determine not only the amounts of RNR subunits, but the amounts of active, diferric-tyrosyl radical loaded $\beta_{2}$. If future studies reveal that substoichiometric amounts of $\mathrm{Y} \bullet$ relative to $\mathrm{a}_{2}$ is possible, catalytic $\beta_{2}$ could play a physiological role. We note, however, that regardless of the physiological role of catalytic $\beta_{2}$, the ability of $E$. coli RNR to use $\beta_{2}$ catalytically provides an explanation for the differences in activity of $\alpha_{2}$ and $\beta_{2}$ under standard assay conditions in which each subunit is assayed in the presence of an excess of the second subunit to form the "same" active complex.

Based on studies of class Ia E. coli and human RNRs and class Ib S. sanguinis, B. subtilis, M. tuberculosis, and E. coli RNRs, there are important lessons to be learned for performing reliable assays.

(1) Both $a$ and $\beta$ subunits must be carefully characterized as well as their complexes:

\section{a subunit characterization}

$a$ in general is very air sensitive and its oxidation is often irreversible within a few hours if a reductant such as dithiothreitol (DTT) is not always present during purification and protein storage. $a$ is now known to reside in many distinct quaternary structures (monomer, dimer, non-canonical dimer, tetramer, hexamer, fibrils) and the basis for these changes reside, in part in its $N$-terminal, ATP cone domain or partial cone domains. ${ }^{15}$ Purification of a is often facilitated by appendage of an $\mathrm{N}$-terminal (His) ${ }_{6}$-tag. An altered $\mathrm{N}$-terminally tagged a must thus be used with caution. The recent availability of (His) ${ }_{6}$-SUMO-tags, which allows purification by Ni affinity column, followed by complete removal of the tag with the SUMO protease is recommended. ${ }^{39}$ The $C$-terminal tail of all as is always disordered and houses the two essential cysteines required for the re-reduction of the active site disulfide (Scheme 1). Thus, a tag should never be placed at the $C$-terminal end. Anion exchange purification has worked well for all class I RNRs that we have studied. Purification of $a$ in the presence of small molecule reductant and under anaerobic conditions without a tag, might well avoid many problems.

\section{$\beta$ subunit characterization}

$\beta_{2}$ is a homodimer in all class I RNRs and thus quaternary structure is not an issue. The problems routinely encountered with $\beta_{2} \mathrm{~S}$ are the stability of the $\mathrm{Y} \bullet$ in the metallocofactor and the quantity of metallocofactor inserted during recombinant expression. First, the tyrosyl radicals of the dimetallo-Y• cofactors have widely varying stability. While the E. coli Ia Y• 
has a half-life of 4 days at $4{ }^{\circ} \mathrm{C}$, the human enzyme has a half-life of 30 min at $37{ }^{\circ} \mathrm{C}$. Since $\beta$ is almost always isolated from recombinant sources at an elevated level of expression, it almost never has a full complement of cofactor. ${ }^{40}$ Thus, the cofactor must be assembled and characterized with respect to the metal content and $\mathrm{Y} \bullet \operatorname{per} \beta$. The loading of $\beta$ with 0.5 to 1 $\mathrm{Y} \bullet / \beta$, from the self-assembly process in vitro $^{22}$ is distinct from in vivo studies ${ }^{38,41}$ thus far reported; more basic biology and biochemical studies are required to understand how the cofactors are assembled in cells. In the optimized assembly of the $E$. coli $\beta_{2}$ cofactor, while there are 3.6 irons $/ \beta_{2}$, there are typically $1.2 \mathrm{Y} \bullet / \beta_{2}{ }^{42}$ Sixty percent of the cluster is the active $\mathrm{Fe}^{3+}{ }_{2-\mathrm{Y}} \cdot$ cofactor and $40 \%$ is inactive, tyrosyl radical reduced, $\mathrm{Fe}^{3+}{ }_{2}-\mathrm{YOH}$. Thus, in most assays that are $1: 1 \alpha / \beta, \beta_{2}$ always acts catalytically! The cofactor assembly has been optimized for the E. coli RNR, but each $\beta_{2}$ is distinct. Since the $\mathrm{Y} \bullet$ is a key indicator of activity, optimizing cluster assembly for assays is essential.

\section{$\alpha / \beta$ complex characterization}

Although the $\alpha$ and $\beta$ subunits in all class I RNRs are structurally homologous, the quaternary structures of $\alpha$ and the $\alpha / \beta$ complex are unique and appear to be protein concentration- and nucleotide-dependent. While $\alpha$ alone has been found as noted above in many states, it also forms inactive complexes with $\beta\left(\alpha_{4} \beta_{4}\right)$ in $E$. coli 19 and in a helical $\alpha / \beta$ fibril in $B$. subtilis. ${ }^{43}$ Some have proposed that $\alpha_{6} / \beta_{2}$ forms exist in $S$. cerevisiae and human RNRs, ${ }^{44}$ but in our opinion, the activity of this state is in question. Not much is known about the equilibria of these species and how other factors in cells affect them. Thus, the conditions used to study RNRs must be carefully described.

\section{$K_{d}$ for subunit interactions}

The $K_{\mathrm{d}}$ for subunit interaction is also essential to determine. If the $K_{\mathrm{d}}$ is weak, $(0.2 \mu \mathrm{M})$ and the protein is diluted during purification or in crude lysates, activity can be lost because the active complex does not form or the subunits dissociate and the active complex cannot reform. An important issue to consider is that $K_{\mathrm{dS}}$ are challenging to determine, if one does not understand the quaternary structure of each subunit.

(2) Redox reductants to cycle RNRs for multiple turnovers must be identified:

Given the requirement for re-reduction of the disulfide in a accompanying formation of each dNDP, the endogenous reductant in each organism needs to be determined. DTT is often used to reduce previously unidentified as because the protein reductant(s) are initially unknown. For this case, the efficiency varies widely and is dependent on the concentration of reductant. ${ }^{45}$ As almost all organisms have multiple candidates for a reduction including TR/TRR, glutaredoxin/glutaredoxin reductase/glutathione, $\mathrm{NrdH}$, etc., identification of the most efficient system is very important to obtain the most robust assay for inhibitor(s) discovery.

(3) Assay conditions musts have optimized $\alpha: \beta$ and reductant ratios:

Knowledge about the RNR and the organism from which it is obtained is a pre-requisite for the best experimental design. Our experiences with class Ia RNRs (E. coli, human, and $S$. cerevisiae) and class Ib RNRs ( $S$. sanquinis, B. subtilis, and $M$. tuberculosis) have suggested 
the following general protocol. First, assume that the ratio of $\alpha: \beta$ is $1: 1$ and that $\alpha_{2} \beta_{2}$ is the active form. We believe this is a reasonable assumption based on the recent structures of an active E. coli Ia RNR ${ }^{15}$ and structures of $B$. subtilis ${ }^{43}$ and $S$. typhimurium ${ }^{46} \mathrm{Ib}_{\text {RNRs. }}$ Second, determine the concentration of RNR in the organism of interest and identify the endogenous reductant. Third, measure the activity of each RNR over the protein concentration range from 0.5 to $5 \times$ estimated physiological levels. The results from some recent studies on $S$. sanquinis, ${ }^{47}$ B. subtilis ${ }^{39,48}$ and $M$. tuberculosis dimanganese-tyrosyl radical RNRs using this approach are shown in Fig. S4. The apparent $K_{\mathrm{m}}$ values obtained from these analyses are lower ( $K_{\mathrm{m}}$ of $6.4 \mathrm{nM}, 0.025 \mu \mathrm{M}$, and $0.16 \mu \mathrm{M}$, respectively) than a similar experiment with $E$. coli and human Ia RNRs (apparent $K_{\mathrm{m}}$ of $0.2 \mu \mathrm{M}$ ) suggesting "tighter" $\alpha / \beta$ affinity. However, efforts to isolate active $\alpha / \beta$ complexes of these Ib RNRs using several biophysical methods (size exclusion chromatography and analytical ultracentrifugation) all revealed that the subunit behavior, as with Ia E. coli RNR, is dynamic. Our studies on $M$. $t b$ RNR have shown that it uses a dimanganese-tyrosyl radical cofactor, possesses high activity and behaves similarly to the $B$. subtilis and $S$. sanguinis enzymes, in contrast with the recent report of Fe-loaded NrdF2. ${ }^{49}$ In the case of the $B$. subtilis RNR, the assay approach described above appears to avoid the known complexities associated with complex quaternary structure ${ }^{43}$ in this system.

(4) The rate limiting steps for single vs multiple turnovers of RNR must be considered:

Studies on E. coli Ia RNR have shown that the rate limiting steps for single turnover is described by a rate constant of $8-9 \mathrm{~s}^{-1}$ whereas multiple turnovers of RNR yields a rate constant of $1-2 \mathrm{~s}^{-1}$. Thus, experiments on RNR are typically performed under two general conditions: one in the steady state with endogenous reductant and the other under "single" turnover in the absence of a reducing system. In the former case, low protein amounts are sufficient and the protocol described in (3) is recommended in search of small molecule RNR inhibitors. Once an inhibitor is identified, the target of the inhibition (tyrosyl radical reduction in $\beta$, active site modification in $a$, altered quaternary structure of $a$ or $\alpha / \beta$, etc.) can be identified using the "single" turnover approach. In this case, elevated levels of protein are required so that the method of analysis can detect a single equivalent or less of intermediate or product.

\section{CONCLUDING REMARKS}

We highlight here that studies on newly discovered RNRs must identify the system and describe the assay conditions carefully. Heroic studies are now turning to examining RNR in vivo owing to the importance of inhibiting the enzyme for development of antibacterial and anticancer therapies. Considering the complexity of in vitro RNR assays, as shown herein for $E$. coli class I RNR, the design of in vivo assays ${ }^{50}$ for such studies will be extremely challenging. Understanding RNR's properties is important for uncovering its role in nucleotide metabolism in general, and key for development of assays for new RNR inhibitors in vitro and in vivo. 


\section{Supplementary Material}

Refer to Web version on PubMed Central for supplementary material.

\section{ACKNOWLEDGEMENT}

The authors gratefully the NIH for funding, DGN (GM 47274) and JS (GM 29595) and LO acknowledges the NSF for a graduate fellowship.

\section{ABBREVIATIONS}

$\begin{array}{ll}\text { RNR } & \text { class Ia ribonucleotide reductase from E. coli } \\ \text { SF } & \text { stopped flow } \\ \text { RCQ } & \text { rapid chemical quench } \\ \text { TR } & \text { thioredoxin } \\ \text { TRR } & \text { thioredoxin reductase }\end{array}$

\section{REFERENCES}

(1). Stubbe J, and van der Donk WA (1998) Protein radicals in enzyme catalysis. Chem. Rev 98, 705762. [PubMed: 11848913]

(2). Jordan A, and Reichard P (1998) Ribonucleotide reductases. Annu. Rev. Biochem 67, 71-98. [PubMed: 9759483]

(3). Brown NC, and Reichard P (1969) Ribonucleoside diphosphate reductase. Formation of active and inactive complexes of proteins B1 and B2. J. Mol. Biol 46, 25-38. [PubMed: 4902211]

(4). Thelander L (1973) Physicochemical characterization of ribonucleoside diphosphate reductase from Escherichia coli. J. Biol. Chem 248, 4591-4601. [PubMed: 4578086]

(5). Minnihan EC, Ando N, Brignole EJ, Olshansky L, Chittuluru J, Asturias FJ, Drennan CL, Nocera DG, and Stubbe $J$ (2013) Generation of a stable, aminotyrosyl radical-induced $a_{2} \beta_{2}$ complex of Escherichia coli class Ia ribonucleotide reductase. Proc. Natl. Acad. Sci. U.S.A 110, 3835-3840. [PubMed: 23431160]

(6). Uhlin U, and Eklund H (1994) Structure of ribonucleotide reductase protein R1. Nature 370, 533539. [PubMed: 8052308]

(7). Stubbe J, Nocera DG, Yee CS, and Chang MCY (2003) Radical initiation in the class I ribonucleotide reductase: long-range proton-coupled electron transfer? Chem. Rev 103, 2167 2201. [PubMed: 12797828]

(8). Shao J, Zhou B, Chu B, and Yen Y (2006) Ribonucleotide reductase inhibitors and future drug design. Curr. Cancer Drug Targets 6, 409-431. [PubMed: 16918309]

(9). Cerqueira NMFSA, Pereira S, Fernandes PA, and Ramos MJ (2005) Overview of ribonucleotide reductase inhibitors: an appealing target in anti-tumour therapy. Curr. Med. Chem 12, 12831294. [PubMed: 15974997]

(10). Wnuk SF, and Robins MJ (2006) Ribonucleotide reductase inhibitors as anti-herpes agents. Antiviral Res. 71, 122-126. [PubMed: 16621038]

(11). Ravichandran KR, Minnihan EC, Wei Y, and Stubbe J (2015) Reverse electron transfer completes the catalytic cycle in a 2,3,5-trifluorotyrosine-substituted ribonucleotide reductase. J. Am. Chem. Soc 137, 14387-14395. [PubMed: 26492582]

(12). Brown NC, Canellakis ZN, Lundin B, Reichard P, and Thelander L (1969) Ribonucleoside diphosphate reductase. Purification of the two subunits, proteins B1 and B2. Eur. J. Biochem 9, 561-573. [PubMed: 4896737] 
(13). Climent I, Sjöberg B-M, and Huang CY (1991) Carboxyl-terminal peptides as probes for Escherichia coli ribonucleotide reductase subunit interaction: kinetic analysis of inhibition studies. Biochemistry 30, 5164-5171. [PubMed: 2036382]

(14). Ge J, Yu G, Ator MA, and Stubbe J (2003) Pre-steady-state and steady-state kinetic analysis of $E$. coli class I ribonucleotide reductase. Biochemistry 42, 10071-10083. [PubMed: 12939135]

(15). Greene BL, Kang G, Cui C, Bennati M, Nocera DG, Drennan CL, and Stubbe J (2020) Ribonucleotide reductases (RNRs): structure, chemistry, and metabolism suggest new therapeutic targets. Annu. Rev. Biochem 89, in press.

(16). Mao SS, Holler TP, Yu GX, Bollinger JM, Booker S, Johnston MI, and Stubbe J (1992) A model for the role of multiple cysteine residues involved in ribonucleotide reduction: amazing and still confusing. Biochemistry 31, 9733-9743. [PubMed: 1382592]

(17). Kasrayan A, Birgander PL, Pappalardo L, Regnström K, Westman M, Slaby A, Gordon E, and Sjöberg BM (2004) Enhancement by effectors and substrate nucleotides of R1-R2 interactions in Escherichia coli class Ia ribonucleotide reductase. J. Biol. Chem 279, 31050--31057. [PubMed: 15145955]

(18). Lou M, Liu Q, Ren G, Zeng J, Xiang X, Ding Y, Lin Q, Zhong T, Liu X, Zhu L, Qi H, Shen J, Li $\mathrm{H}$, and Shao J (2017) Physical interaction between human ribonucleotide reductase large subunit and thioredoxin increases colorectal cancer malignancy. J. Biol. Chem 292, 9136-9149. [PubMed: 28411237]

(19). Ando N, Brignole EJ, Zimanyi CM, Funk MA, Yokoyama K, Asturias FJ, Stubbe J, and Drennan CL (2011) Structural interconversions modulate activity of Escherichia coli ribonucleotide reductase. Proc. Natl. Acad. Sci. U.S.A 108, 21046-21051. [PubMed: 22160671]

(20). Minnihan EC, Seyedsayamdost MR, Uhlin U, and Stubbe J (2011) Kinetics of radical intermediate formation and deoxynucleotide production in 3-aminotyrosine-substituted Escherichia coli ribonucleotide reductases. J. Am. Chem. Soc 133, 9430-9440. [PubMed: 21612216]

(21). Yokoyama K, Uhlin U, and Stubbe J (2010) Site-specific incorporation of 3-nitrotyrosine as a probe of $\mathrm{p} K_{\mathrm{a}}$ perturbation of redox-active tyrosines in ribonucleotide reductase. J. Am. Chem. Soc. 132, 8385-8397. [PubMed: 20518462]

(22). Atkin CL, Thelander L, Reichard P, and Lang G (1973) Iron and free radical in ribonucleotide reductase. Exchange of iron and Mössbauer spectroscopy of the protein B2 subunit of the Escherichia coli enzyme. J. Biol. Chem 248, 7464-7472. [PubMed: 4355582]

(23). Bollinger JM Jr, Tong WH, Ravi N, Huynh BH, Edmonson DE, and Stubbe J (1995) Use of rapid kinetics methods to study the assembly of the diferric-tyrosyl radical cofactor of E. coli ribonucleotide reductase. Meth Enzymol 258, 278-303. [PubMed: 8524156]

(24). Seyedsayamdost MR, Xie J, Chan CTY, Schultz PG, and Stubbe J (2007) Site-specific insertion of 3-aminotyrosine into subunit $a_{2}$ of $E$. coli ribonucleotide reductase: Direct evidence for involvement of Y730 and Y731 in radical propagation. J. Am. Chem. Soc 129, 15060-15071. [PubMed: 17990884]

(25). Chivers PT, Prehoda KE, Volkman BF, Kim BM, Markley JL, and Raines RT (1997) Microscopic $\mathrm{p} K_{\mathrm{a}}$ values of Escherichia coli thioredoxin. Biochemistry 36, 14985-14991. [PubMed: 9398223]

(26). Russel M, and Model P (1985) Direct cloning of the trxB gene that encodes thioredoxin reductase. J. Bacteriol 163, 238-242. [PubMed: 2989245]

(27). Hassan AQ, Wang Y, Plate L, and Stubbe J (2008) Methodology to probe subunit interactions in ribonucleotide reductases. Biochemistry 47, 13046-13055. [PubMed: 19012414]

(28). Steeper JR, and Steuart CD (1970) A rapid assay for CDP reductase activity in mammalian cell extracts. Anal. Biochem. 34, 123-130. [PubMed: 5440901]

(29). Aberg A, Hahne S, Karlsson M, Larsson A, Ormo M, Ahgren A, and Sjöberg BM (1989) Evidence for two different classes of redox-active cysteines in ribonucleotide reductase of Escherichia coli. J. Biol. Chem 264, 12249-12252. [PubMed: 2663852]

(30). Climent I, Sjöberg B-M, and Huang CY (1992) Site-directed mutagenesis and deletion of the carboxyl terminus of Escherichia coli ribonucleotide reductase protein R2. Effects on catalytic activity and subunit interaction. Biochemistry 31, 4801-4807. [PubMed: 1591241] 
(31). Ekberg M, Sahlin M, Eriksson M, and Sjöberg BM (1996) Two conserved tyrosine residues in protein R1 participate in an intramolecular electron transfer in ribonucleotide reductase. J. Biol. Chem 271, 20655-20659. [PubMed: 8702814]

(32). Rofougaran R, Crona M, Vodnala M, Sjöberg B-M, and Hofer A (2008) Oligomerization status directs overall activity regulation of the Escherichia coli class Ia ribonucleotide reductase. J. Biol. Chem 283, 35310-35318. [PubMed: 18835811]

(33). Funk MA, Brignole EJ, and Drennan CL Disruption of an oligomeric interface prevents allosteric inhibition of Escherichia coli class Ia ribonucleotide reductase. (2018) J. Biol. Chem. 293, 10404-10412. [PubMed: 29700111]

(34). Ormö M, and Sjöberg B-M (1990) An ultrafiltration assay for nucleotide binding to ribonucleotide reductase. Anal. Biochem 189, 138-141. [PubMed: 2278383]

(35). Von Döbeln U, and Reichard P (1976) Binding of substrates to Escherichia coli ribonucleotide reductase. J. Biol. Chem 251, 3616-3622. [PubMed: 776972]

(36). Zimanyi CM, Ando N, Brignole EJ, Asturias FJ, Stubbe J, and Drennan CL (2012) Tangled up in knots: structures of inactivated forms of E. coli class Ia ribonucleotide reductase. Structure 20, 110. [PubMed: 22244750]

(37). Licht SS, Lawrence C, C. L., and Stubbe J (1999) Class II ribonucleotide reductases catalyze carbon-cobalt bond reformation on every turnover. J. Am. Chem. Soc 121, 7463-7468.

(38). Hristova D, Wu CH, Jiang W, Krebs C, and Stubbe J (2008) Importance of the maintenance pathway in the regulation of the activity of Escherichia coli ribonucleotide reductase. Biochemistry 47, 3989-3999. [PubMed: 18314964]

(39). Parker MJ, Ailiena, Maggiolo AO, Thomas WC, Kim A, Meisburger SP, Ando N, Boal A,K, and Stubbe J (2018) An endogenous dAMP ligand in Bacillus subtilis class Ib RNR promotes assembly of a noncanonical dimer for regulation by dATP. Proc. Natl. Acad. Sci. U.S.A 115, E4594-E4603. [PubMed: 29712847]

(40). Aye Y, and Stubbe J Clofarabine $5^{\prime}$-di and -triphosphates inhibit human ribonucleotide reductase by altering the quaternary structure of its large subunit. Proc. Natl. Acad. Sci. U.S.A 108, 98159820. [PubMed: 21628579]

(41). Hristova D, Perlstein DL, Zhang Z, Huang M, and Stubbe J (2006) Determination of the in vivo stoichiometry of tyrosyl radical per beta betá in Saccharomyces cerevisiae ribonucleotide reductase. Biochemistry 45, 12282-12294. [PubMed: 17014081]

(42). Bollinger JM (1983) On the chemical mechanism of assembly of the tyrosyl radical-dinulcear iron cluster cofactor of E. coli ribonucleotide reductase. Ph.D. Thesis Massachusetts Institute of Technology, https://dspace.mit.edu/handle/1721.1/12581

(43). Thomas WC, Brooks FP, Burnim AA, Bacik J-P, Stubbe J, Kaelber JT, Chen JZ, and Ando N (2019) Convergent allostery in ribonucleotide reductase, Nat. Commun 10, 2653. [PubMed: 31201319]

(44). Rofougaran R, Vodnala M, and Hofer A (2006) Enzymatically active mammalian ribonucleotide reductase exists primarily as an alpha(6)beta(2) J. Biol. Chem 281, 27705-27711. [PubMed: 16861739]

(45). Mao SS, Johnston M. I. Bollinger, J. M., and Stubbe J (1989) Mechanism-based inhibition of a mutant Escherichia coli ribonucleotide reductase (cysteine-225----serine) by its substrate CDP. Proc. Natl. Acad. Sci. U.S.A 86, 1485-1489. [PubMed: 2493643]

(46). Uppsten M, Färnegårdh M, Domkin V and Uhlin U (2006) The first holocomplex structure of ribonucleotide reductase gives new insight into its mechanism of action. J. Mol. Biol 359, 365377. [PubMed: 16631785]

(47). Makhlynets O, Boal AK, Rhodes DV, Kitten D, Rosenzweig AC and Stubbe J (2014) Streptococcus sanguinis Class Ib Ribonucleotide reductase: High activity with both iron and manganese cofactors and structural insights. J. Biol. Chem 289, 6259-6272. [PubMed: 24381172]

(48). Parker MJ, Zhu X, and Stubbe J (2014) Bacillus subtilis class Ib ribonucleotide reductase: High activity and dynamic subunit interactions. Biochemistry 53, 766-776. [PubMed: 24401092] 
(49). Hammerstad M, Røhr AK, Andersen NH, Gräslund A, Högbom M, and Andersson KK (2014) The class Ib ribonucleotide reductase from Mycobacterium tuberculosis has two active R2F subunits. J. Biol. Inorg. Chem 19, 893-902. [PubMed: 24585102]

(50). Tholander F, Sjöberg BM. (2012) Discovery of antimicrobial ribonucleotide reductase inhibitors by screening in microwell format. Proc. Natl. Acad. Sci. U.S.A 109, 9798-9803. [PubMed: 22665797] 
(a)

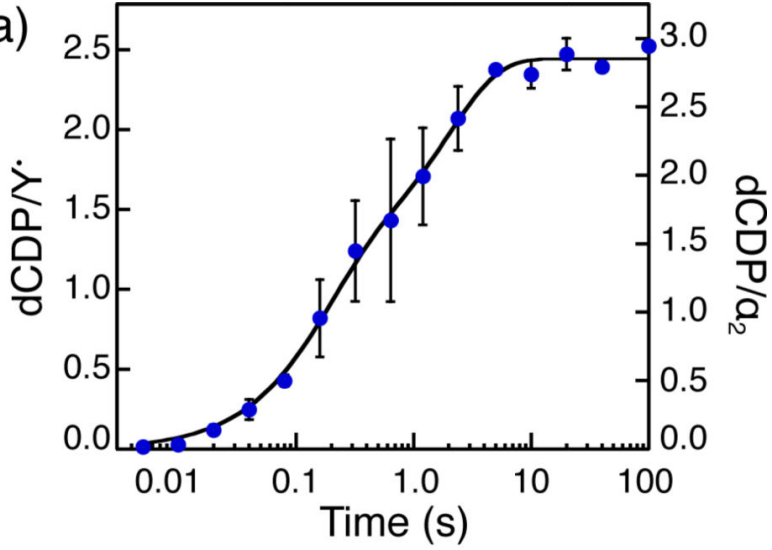

(b)
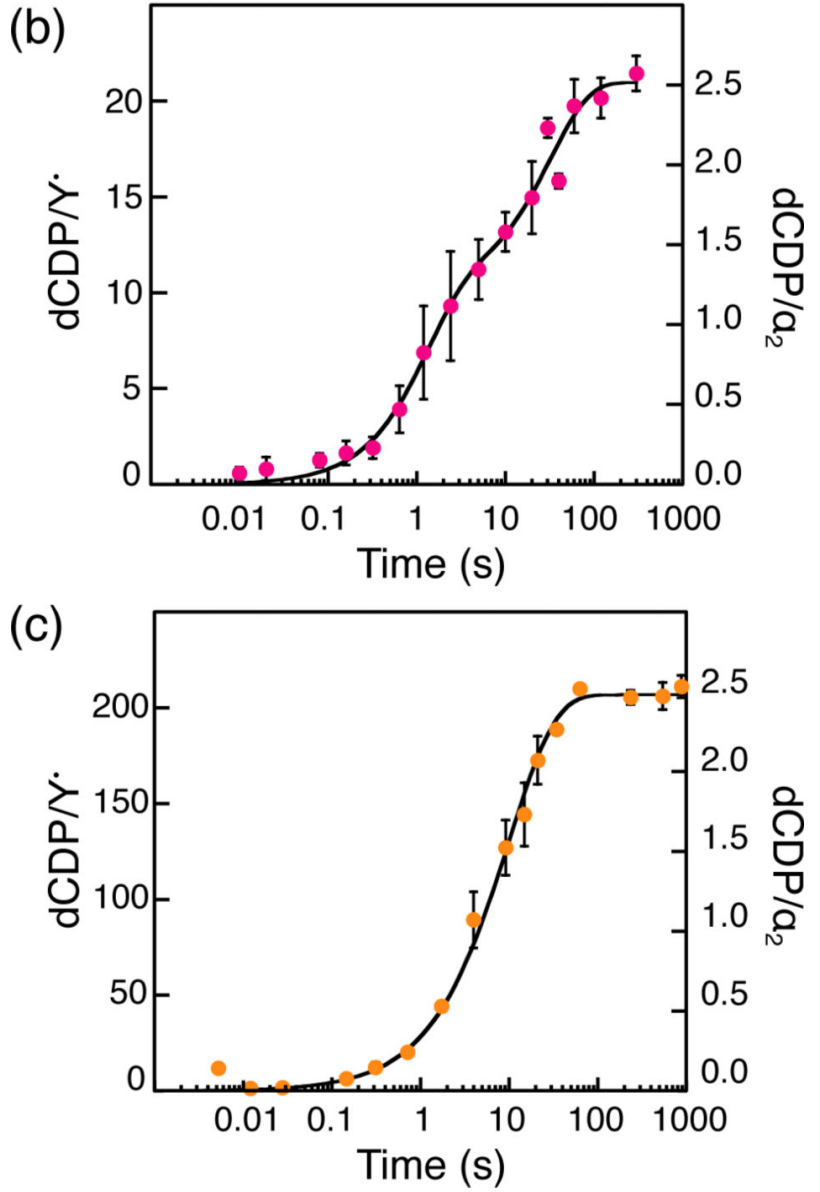

Figure 1.

Product formation kinetics measured by RCQ in the absence of reductant. Final reaction mixtures contained $10 \mu \mathrm{M} \mathrm{a}_{2}, 0.5 \mathrm{mM}$ CDP, $3 \mathrm{mM}$ ATP and (a) $10 \mu \mathrm{M}$, (b) $1 \mu \mathrm{M}$, or (c) 0.1 $\mu \mathrm{M} \beta_{2}$ as indicated. Circles and error bars represent the mean and average error of 2 trials, respectively. Black traces represent fits to Eq. 1 (a and b) or Eq. 2 (c) and produced the rate constants and amplitudes listed in Table 1. 
(a)

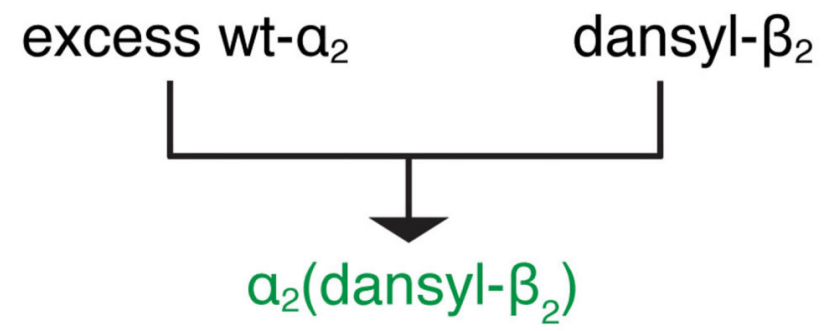

(b)

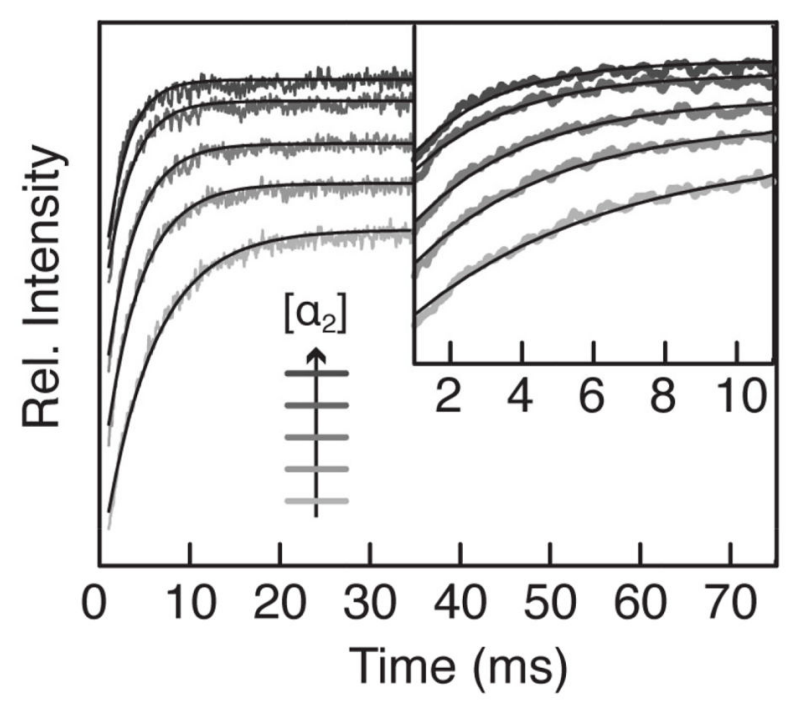

(c)

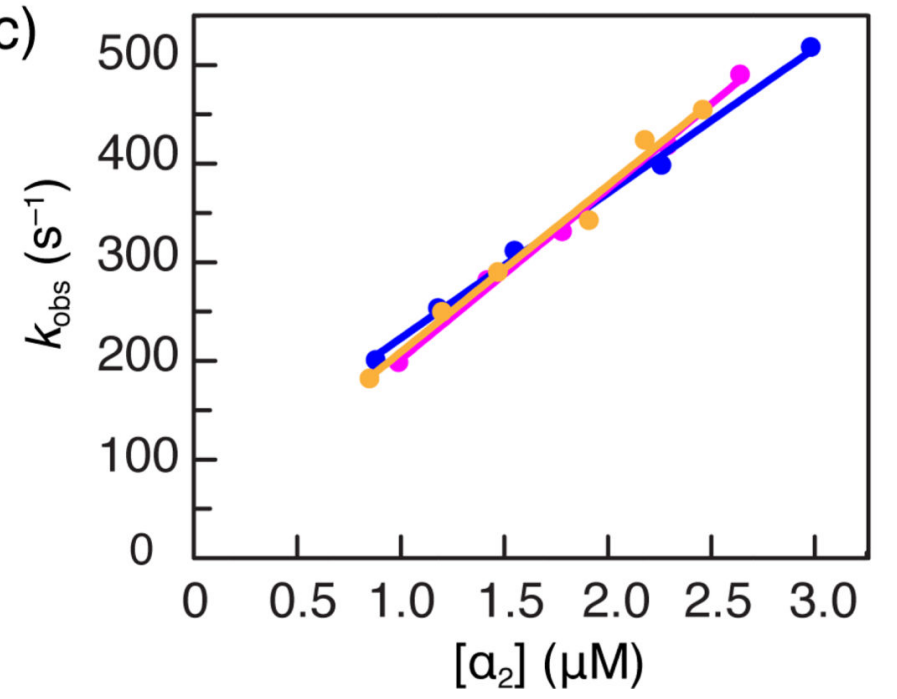

Figure 2.

Diagram describing SF fluorescence experiment to measure (a) $k_{\text {assoc }}$, where green indicates the highly fluorescent state. (b) To extract $k_{\text {assoc }}$, the fluorescence intensity was measured under pseudo-first order conditions for a range of [ $\left.a_{2}\right]$, and fit to Eq. 2 (black traces, 1 set of 3 data sets shown). (c) $k_{\text {obs }}$ (points) obtained in this way were then plotted versus [ $a_{2}$ ], and fit (lines) to Eq. 3 to obtain $k_{\text {assoc }}$ from the slope of fitted lines. 
(a)

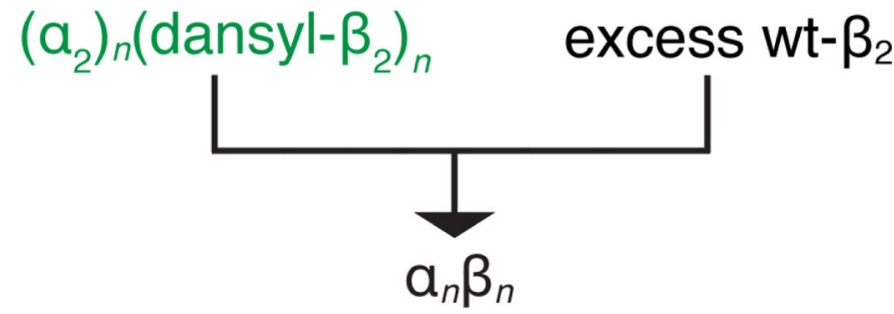

(b)

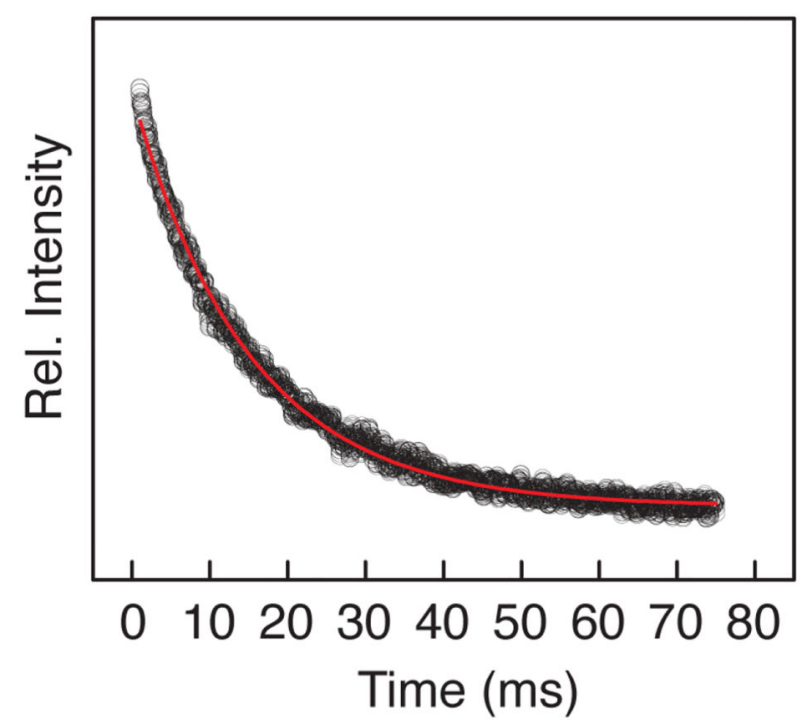

(c)

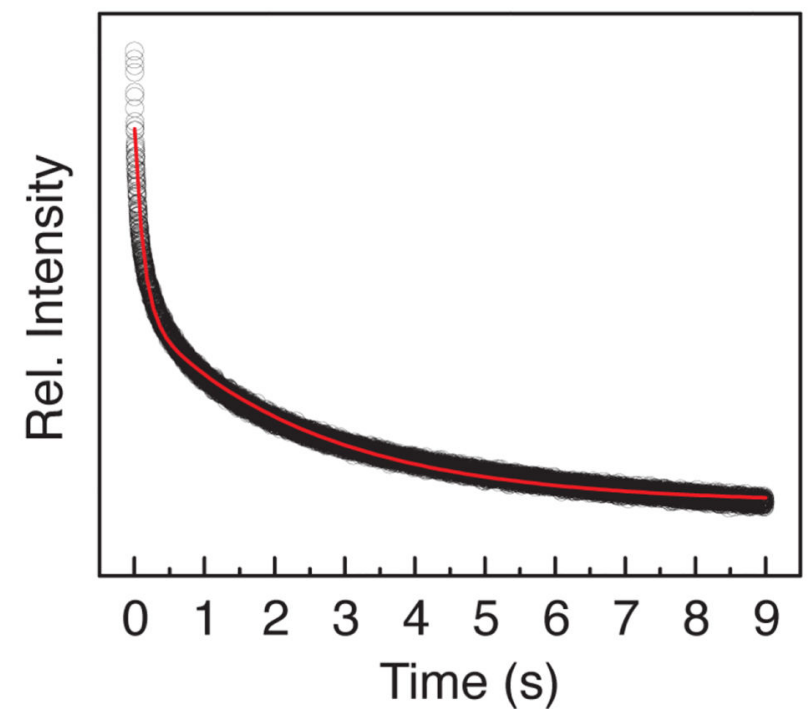

Figure 3.

Scheme for SF fluorescence experiment to determine $k_{\text {dissoc }}(\mathrm{a})$, where green indicates the highly fluorescent state and $n=1$ in (b) and 2 in (c). Fluorescence decay kinetics were measured in the presence of $0.5 \mathrm{mM} \mathrm{CDP}$ and $1.5 \mathrm{mM}$ ATP (b), and $50 \mu \mathrm{M}$ dATP (c). Black circles represent averages of $15 \mathrm{SF}$ traces, and lines are fits to Eq. 2 (b) or 1 (c). The data shown represent 1 of 3 independent trials, the averages and sd of which are presented in Table 2. 
(a)

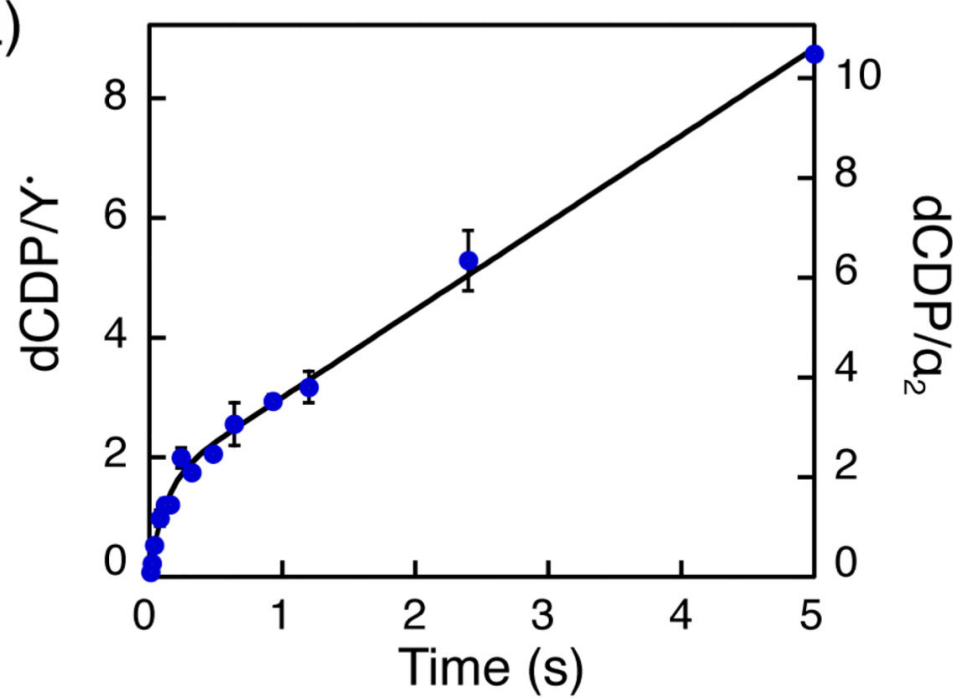

(b)

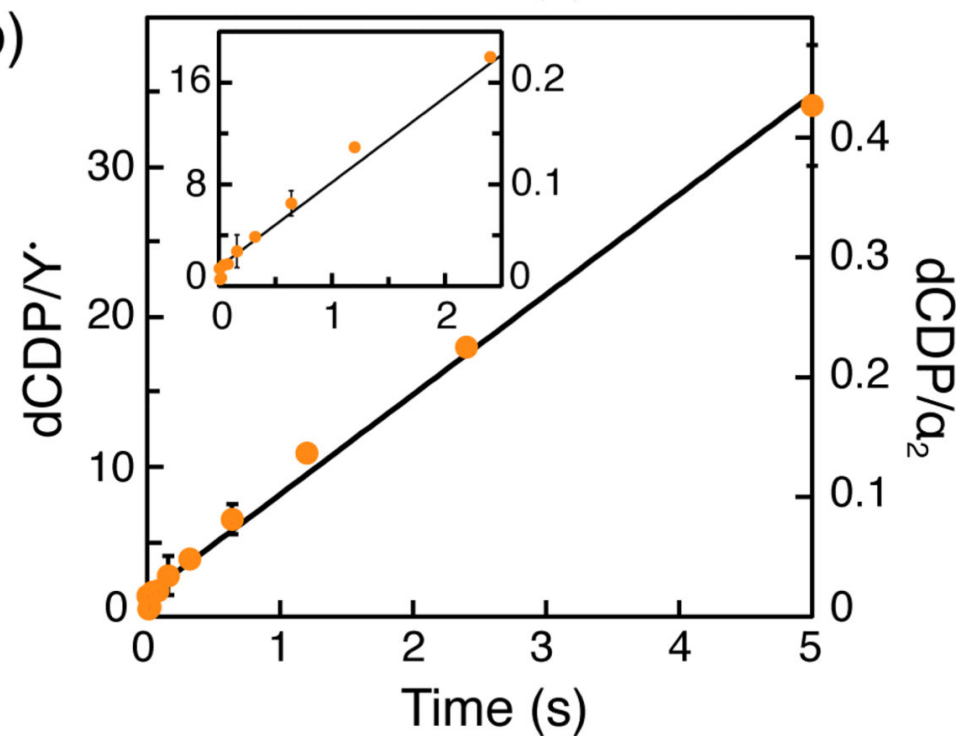

Figure 4.

dCDP formation kinetics measured by RCQ in the presence of TR/TRR/NADPH. Reaction mixtures contained $a_{2}(10 \mu \mathrm{M}),\left[5-{ }^{3} \mathrm{H}\right]-\mathrm{CDP}(1 \mathrm{mM})$, ATP $(3 \mathrm{mM})$, TR $(40 \mu \mathrm{M})$, TRR $(0.8$ $\mu \mathrm{M})$, NADPH ( $1 \mathrm{mM}$ ), and $\beta_{2}$ at either $10 \mu \mathrm{M}$, (a), or $0.1 \mu \mathrm{M}$, (b). Data points represent the averages of two trials. Black traces represent fits to Eq. 4 (a) or 5 (b). 


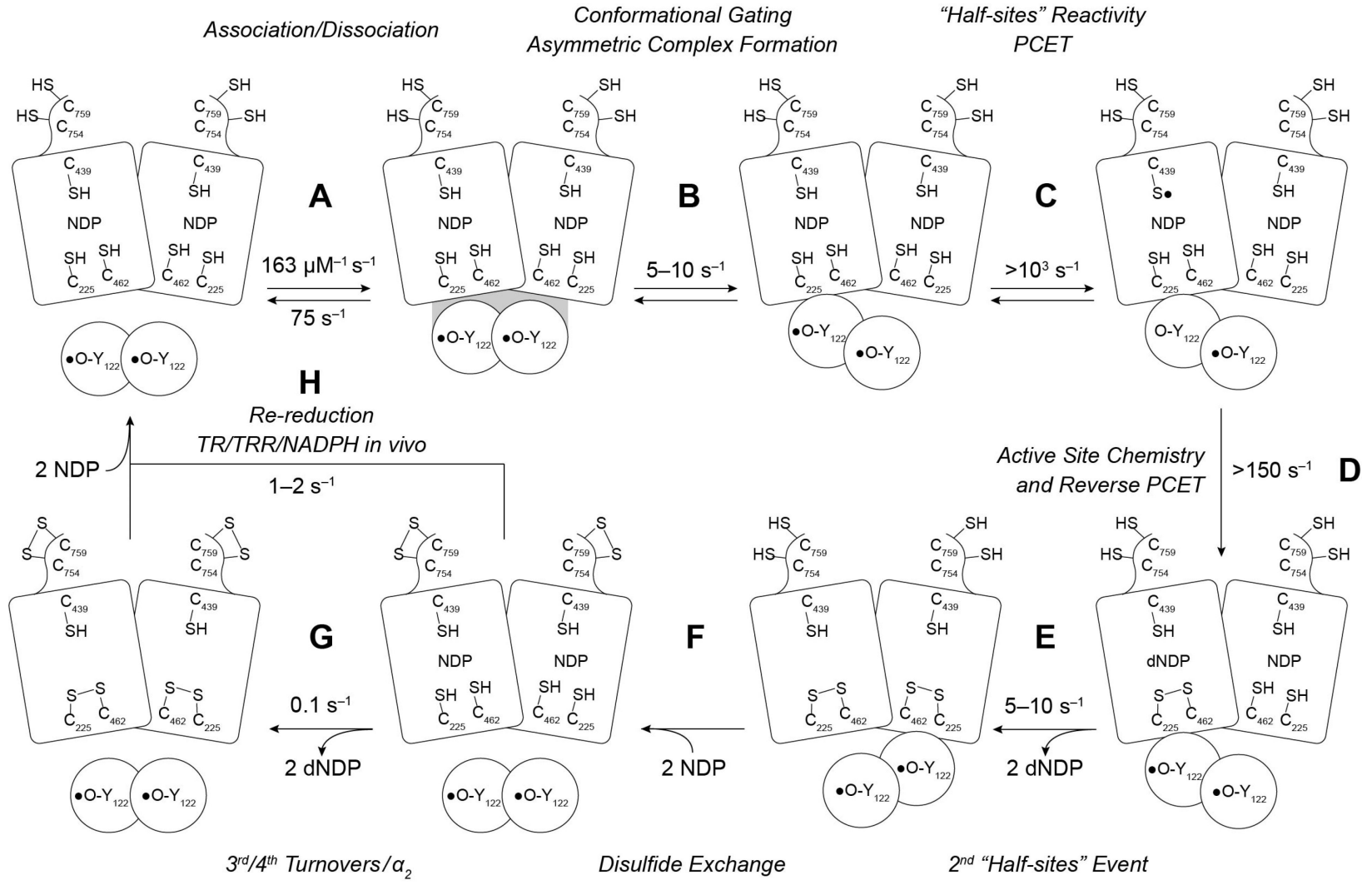

Scheme 1.

Updated model for kinetics of dNDP formation in the absence of endogenous reductant at 5$10 \mathrm{~s}^{-1}$ (steps A-G), and in the presence of endogenous reductant and multiple turnovers (step H) at $1-2 \mathrm{~s}^{-1}$. 
Table 1.

$\mathrm{dCDP}$ formation kinetics at varying ratios of $a: \beta$ in the absence of reductant.

\begin{tabular}{|ccccccccc|}
\hline $\boldsymbol{a}_{\mathbf{2}}(\boldsymbol{\mu M})$ & $\boldsymbol{\beta}_{\mathbf{2}}(\boldsymbol{\mu M})$ & \multicolumn{3}{c|}{ First phase } & \multicolumn{5}{c|}{ Second phase } \\
& & $\boldsymbol{k}_{\mathbf{1}}\left(\mathbf{s}^{\mathbf{- 1}}\right)$ & $\mathbf{d C D P} / \mathbf{a}_{\mathbf{2}}$ & $\mathbf{d C D P} / \mathbf{Y}^{\boldsymbol{a}}$ & $\boldsymbol{k}_{\mathbf{2}}\left(\mathbf{s}^{\mathbf{- 1}}\right)$ & $\mathbf{d C D P} / \mathbf{a}_{\mathbf{2}}$ & $\mathbf{d C D P} / \mathbf{Y}^{\boldsymbol{a}}$ & $\boldsymbol{k}_{\mathrm{cat}}^{\boldsymbol{b}}\left(\mathbf{s}^{\mathbf{- 1}}\right)$ \\
\hline 10 & 10 & $6(1)$ & $1.3(2)$ & $1.1(1)$ & $0.51(8)$ & $1.6(2)$ & $1.3(1)$ & $8(1)$ \\
10 & 1 & $0.8(2)$ & $1.4(1)$ & $10(1)$ & $0.030(7)$ & $1.1(1)$ & $11(1)$ & $8(2)$ \\
10 & 0.1 & $0.046(2)$ & $2.5(1)$ & $207(3)$ & - & - & - & $9.5(4)$ \\
1 & 1 & $6(1)$ & $1.5(2)$ & $1.2(1)$ & $0.9(1)$ & $1.5(2)$ & $1.2(1)$ & $8(1)$ \\
\hline
\end{tabular}

${ }^{a} \mathrm{Y} \bullet$ amount used in the $\mathrm{dCDP} / \mathrm{Y} \bullet$ calculation was obtained from the moles of $\beta_{2}(87,000 \mathrm{~g} / \mathrm{mol})$ in the reaction mixture and the amount of radical per dimer (1.2).

$b_{k_{\text {cat }}}=\mathrm{A}_{1} k_{1}+\mathrm{A}_{2} k_{2}$, where $\mathrm{A}_{n}$ refers to the amplitude with respect to $\mathrm{Y} \cdot$ 
Table 2.

Association and dissociation rate constants as a function of CDP and effector measured by SF fluorescence spectroscopy.

\begin{tabular}{|c|c|c|}
\hline Substrate/Effector & $k_{\text {assoc }}\left(\mu \mathrm{M}^{-1} \mathrm{~s}^{-1}\right)$ & $k_{\text {dissoc }}\left(\mathrm{s}^{-1}\right)$ \\
\hline CDP/ATP & $163(7)$ & $75(10)$ \\
\hline CDP & $193(7)$ & $93(3)$ \\
\hline ATP & $156(14)$ & $86(10)$ \\
\hline None & $179(11)$ & $109(6)$ \\
\hline $\mathrm{dATP}^{a}$ & & $0.46(4), 7$ (2) \\
\hline
\end{tabular}

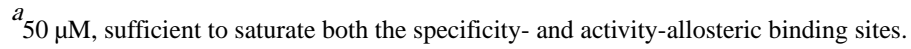


Table 3.

Steady-state turnover numbers for different $\alpha: \beta$ ratios.

\begin{tabular}{|c|c|c|c|}
\hline$\beta_{2}(\mu \mathrm{M})$ & $a_{2}(\mu M)$ & $a_{2} \beta_{2}{ }^{a}\left(\% \beta_{2}\right.$ in complex $)$ & $k_{\text {cat }} b\left(\mathrm{~s}^{-1}\right)$ \\
\hline 0.1 & 10 & 98 & $9.0(3)$ \\
\hline 1 & 10 & 98 & $7.8(1)$ \\
\hline 10 & 10 & 96 & $1.45(4)$ \\
\hline 1 & 1 & 64 & $4.3(2)$ \\
\hline $0.2^{c}$ & 1 & 81 & $6.8(3)$ \\
\hline
\end{tabular}

${ }^{a}$ Assuming a $K_{\mathrm{d}}$ for $\mathrm{a}_{2} \beta_{2}$ of $0.2 \mu \mathrm{M}$ (ref 13).

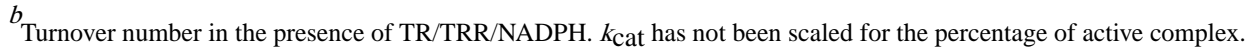

$c_{\text {These are our standard assay conditions to assess }} \beta_{2}$ activity. 
Table 4.

$\mathrm{dCDP}$ formation kinetics at varying ratios of $a: \beta$ in the presence of TR/TRR/NADPH.

\begin{tabular}{|ccccccc|}
\hline$\left[\boldsymbol{a}_{2}\right](\boldsymbol{\mu M})$ & {$\left[\boldsymbol{\beta}_{2}\right](\boldsymbol{\mu M})$} & \multicolumn{3}{c}{ Burst phase } & \multicolumn{2}{c|}{ Linear phase } \\
& & $\boldsymbol{k}_{\text {burst }}\left(\mathbf{s}^{-\mathbf{1}}\right)$ & $\mathbf{d C D P} / \mathbf{a}_{\mathbf{2}}$ & $\mathbf{d C D P} / \mathbf{Y} \bullet$ & $\boldsymbol{k}_{\mathrm{cat}} / \mathbf{a}_{\mathbf{2}}\left(\mathbf{s}^{-\mathbf{1}}\right)$ & $\boldsymbol{k}_{\mathrm{cat}} / \mathbf{Y} \bullet\left(\mathbf{s}^{-\mathbf{1}}\right)$ \\
\hline 15 & $32^{a}$ & 6.1 & 1.4 & 0.7 & 0.9 & - \\
10 & $10^{b}$ & $9 \pm 2$ & $1.9 \pm 0.1$ & $1.5 \pm 0.1$ & $1.85 \pm 0.05$ & $1.45 \pm 0.04$ \\
10 & $0.1{ }^{b}$ & - & - & - & - & $6.8 \pm 0.08$ \\
\hline
\end{tabular}

${ }^{a}$ Adapted from reference $14,0.9 \mathrm{Y} \bullet / \beta_{2}$.

${ }^{b}$ Current work, $1.2 \mathrm{Y} \bullet / \beta_{2}$. 